\title{
Elevation of plasma angiotensin with the development of pulmonary arteriovenous malformations after cavopulmonary shunt
}

Masamichi Ono, MD, PhD*, Norihide Fukushima, MD, PhD, Hajime Ichikawa, MD, Toru Ishizaka, MD, PhD, Yoshiki Sawa, MD, PhD, and Hikaru Matsuda, MD, PhD, Osaka, Japan

$\mathrm{P}$ ulmonary arteriovenous malformation (PAVM) is a serious complication after cavopulmonary shunt. Although the etiology remains unclear, substances in the hepatic venous effluent are thought to play a crucial role in the formation of PAVM, ${ }^{1}$ and reports have shown regression of PAVM after surgical inclusion of hepatic venous flow to the lung. ${ }^{2,3}$ Recently, neurohormonal abnormality was reported after cavopulmonary shunt. ${ }^{4}$ We measured neurohormones in 5 patients after cavopulmonary shunt and obtained evidence that angiotensin has some relation to the development of PAVM.

\section{Clinical Summaries}

A 7-year-old girl (patient 1), 1 year after Fontan completion, was admitted because of dyspnea on effort. Cardiac catheterization demonstrated that only the right lung received the hepatic venous flow, and diffuse PAVM existed in the left lung. An operation was performed to redirect hepatic venous flow to both lungs. Cardiac catheterization demonstrated complete regression of PAVM at 2 postoperative months and trivial PAVM in the left lung at 1 postoperative year. In this period, plasma renin, angiotensin I (AT-I), angiotensin II (AT-II), aldosterone, somatostatin, glucagon, vasoactive intestinal peptide, and atrial natriuretic peptide were measured in blood samples from the superior vena cava, the hepatic vein, the right and left pulmonary arteries, and the aorta at 4 intervals. Consonant with the development and regression of PAVM, AT-I and AT-II levels were increased and decreased in all regions (Table 1). Renin levels remained high even after the operation. Other parameters were within their reference ranges.

As a control group, 4 patients without PAVM after the Fontan operation (patients 2-5) were examined. Two (patients 2 and 3) had

\footnotetext{
From the Division of Cardiovascular Surgery, Department of Surgery, Osaka University Graduate School of Medicine, Osaka, Japan.

Received for publication Jan 26, 2005; accepted for publication Feb 10, 2005 .

Address for reprints: Hikaru Matsuda, MD, PhD, Division of Cardiovascular Surgery, Department of Surgery, Osaka University, Graduate School of Medicine, 2-2-E1 Yamada-oka, Suita, 565-0871, Osaka, Japan (E-mail: matsuda@surg1.med.osaka-u.ac.jp).

* Dr Ono is currently affiliated with the Division of Thoracic and Cardiovascular Surgery, Hannover Medical School, Hannover, Germany.

J Thorac Cardiovasc Surg 2005;130:885-7

0022-5223/\$30.00

Copyright $\odot 2005$ by The American Association for Thoracic Surgery doi:10.1016/j.jtcvs.2005.02.008
}
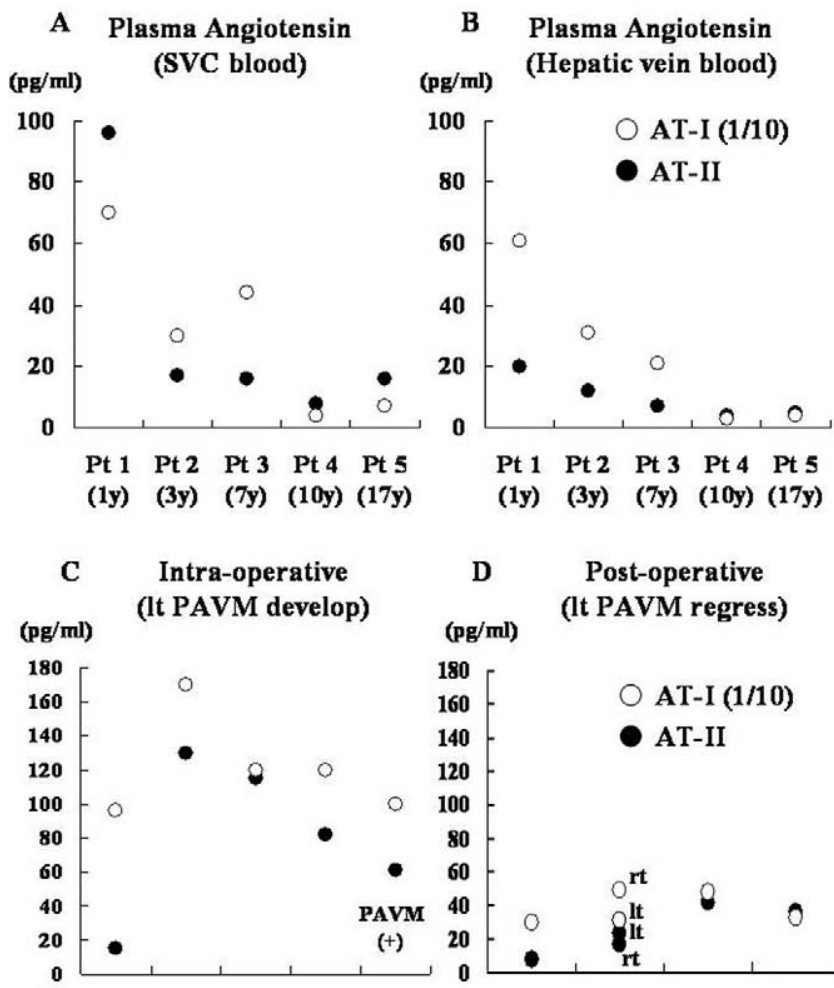

HV rt PA Ao sVC It PA

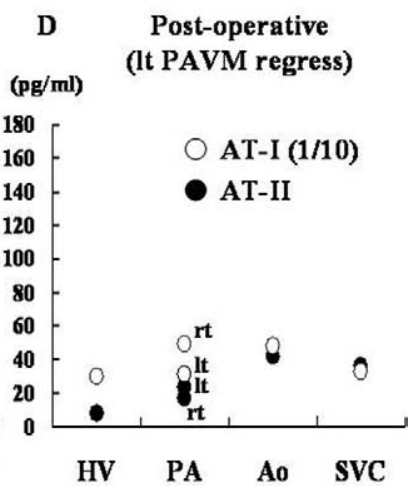

Figure 1. Plasma angiotensin levels after cavopulmonary shunt. $A$ and $B$, Angiotensin levels in superior vena cava blood (A) and hepatic venous blood (B) in each patient at various times after Fontan operation. $C$ and D, Angiotensin levels in patient 1. Values are plotted according to intraoperative (C) and postoperative (D) hepatic venous flows. SVC, Superior vena cava; $P t$, patient; $I t$, left; $r t$, right; $H V$, hepatic vein; $P A$, pulmonary artery; Ao, aorta.

elevated plasma concentrations of AT-I, but the other parameters remained within normal limits.

\section{Discussion}

Neurohormonal activation during the course of several years after cavopulmonary shunt has been demonstrated. ${ }^{4}$ In our study, similarly, 3 of 5 patients showed elevated AT-I (Figure $1, A$ and $B$ ). Moreover, in 1 of our patients AT-I and AT-II increased consonant with the development of PAVM and de- 
TABLE 1. Neurohormonal activity after cavopulmonary shunt

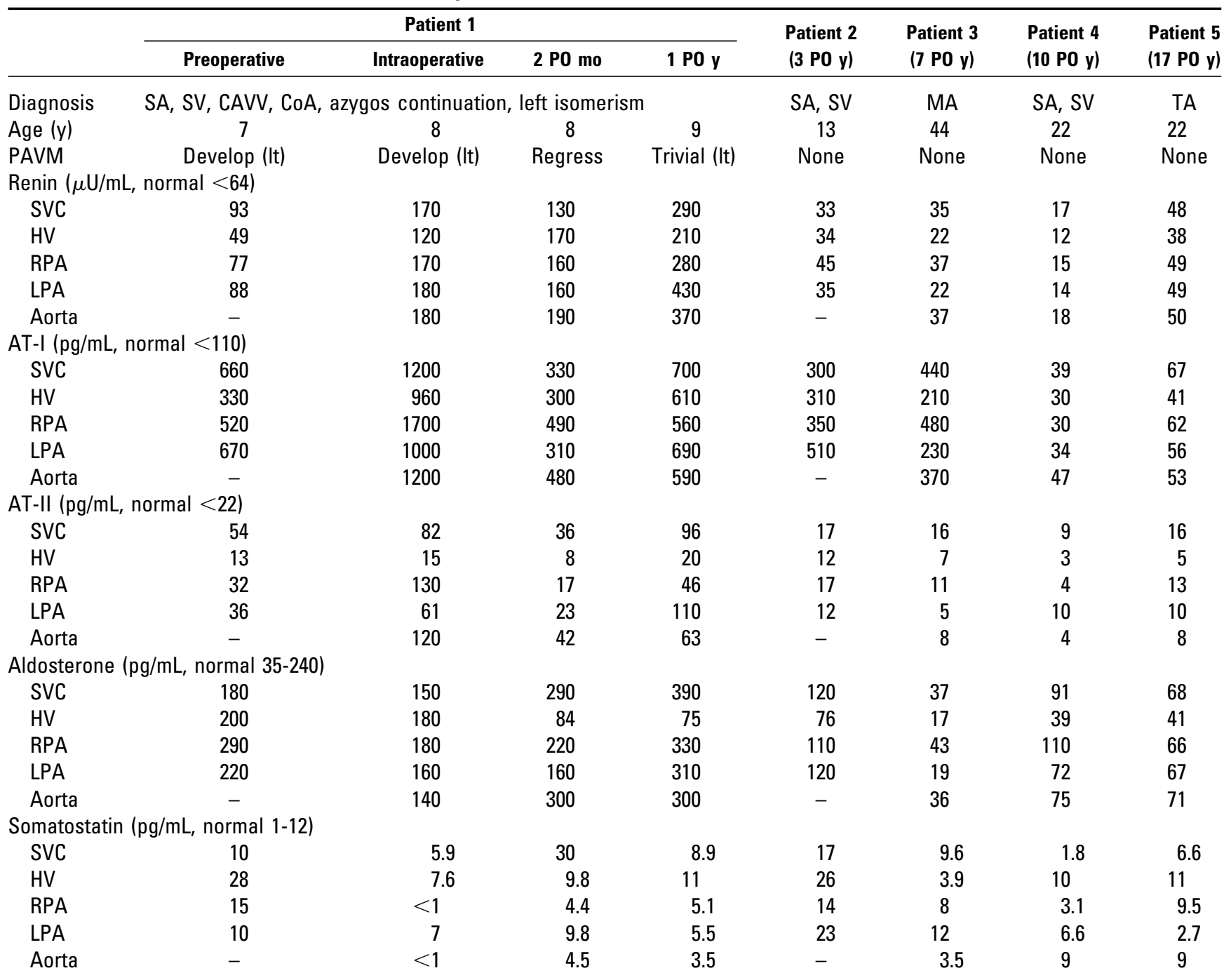

$P O$, Postoperative; $S A$, single atrium; $S V$, single ventricle; $C A V V$, common atrioventricular valve; $C o A$, coarctation of the aorta; $I t$, left; $M A$, mitral atresia; $T A$, tricuspid atresia; $S V C$, superior vena cava; $H V$, hepatic vein; $R P A$, right pulmonary artery; $L P A$, left pulmonary artery.

creased consonant with its regression. To the best of our knowledge, this is the first clinical evidence that angiotensin is elevated in relation to the development of PAVM. Experimentally, Malhotra and colleagues ${ }^{5}$ demonstrated elevation in the expression of AT-II receptors in an ovine model of PAVM. These data suggest that activation of the renin-angiotensin system plays some role in the development of PAVM after cavopulmonary shunt.

In patient 1 , left PAVM developed as a result of the lack of hepatic venous flow. In this period, plasma AT-I and AT-II levels showed differences between the right and the left pulmonary arteries. We plotted these values according to the intraoperative and postoperative hepatic venous flows (Figure 1, $C$ and $D$ ), demonstrating that AT-I and AT-II were activated mainly in the right lung preoperatively. After redirection of hepatic venous flow, both lungs received equal hepatic venous flow and activated AT-I and AT-II. Abnormal circulation in which hepatic venous effluent bypasses one lung may induce abnormal metabolisms of neurohormones such as angiotensin, resulting in abnormal vascular changes after cavopulmonary shunt. It is still unclear whether this abnormal activation of angiotensin during the development of PAVM is primary or secondary. Further investigation, including measurement of angiotensinogen, is needed to clarify this phenomenon.

\section{Conclusion}

We demonstrated elevation of angiotensin during the development of PAVM. Circulation in which hepatic venous flow bypasses the lung seems to induce abnormal metabolism of the rennin-angiotensin system and to play some role in the development of PAVM. 


\section{References}

1. Kawashima Y. Cavopulmonary shunt and pulmonary arteriovenous malformation. Ann Thorac Surg. 1997;63:930-2.

2. Knight WB, Mee RB. A cure for pulmonary arteriovenous fistulas? Ann Thorac Surg. 1995;59:999-1001.

3. Ichikawa $H$, Fukushima $N$, Ono M, Kita $T$, Matsushita $T$, Miyamoto Y, et al. Resolution of pulmonary arteriovenous fistula by redirection of hepatic venous blood. Ann Thorac Surg. 2004;77: 1825-7.

4. Hjortdal VE, Stenbog EV, Ravin HB, Emmertsen K, Jensen KT, Pedersen EB, et al. Neurohormonal activation late after cavopulmonary connection. Heart. 2000;83:439-43.

5. Malhotra SP, Reddy VM, Thelitz S, He YP, Hanley FL, Suleman S, et al. Cavopulmonary anastomosis induces pulmonary expression of the angiotensin II receptor family. J Thorac Cardiovasc Surg. 2002;123:655-60. 